\title{
Quantum-dot-based immunofluorescent imaging of Cancer Marker P53 Detection in Breast Cancer
}

\author{
WANYING XING ${ }^{1}$, QIANG LI ${ }^{2}$, XING REN ${ }^{1}$, GUANG SUN ${ }^{1, a, *}$ \\ ${ }^{1}$ Breast Surgical Department of China-Japan Union Hospital Jilin University, 126 Xiantai Street, \\ Changchun 130033, P. R. China \\ ${ }^{2}$ Hand Surgical Department of China-Japan Union Hospital Jilin University, 126 Xiantai Street, \\ Changchun 130033, P. R. China \\ aemail: guangsun2013@163.com
}

Keywords: Quantum dots; AgInS2/ZnS; Breast cancer; P53; Probes

\begin{abstract}
The study is to design a biomarker based on hydrophilic quantum dots(QDs) can be bound to the P53 protein for diagnoses of breast cancer (BC).To achieve the purpose, we uses the water-soluble quantum (QDs) AgInS2/ZnS connected with P53 monoclonal antibody to design a novel kind of biomarker as a new detection of breast cancer. Significantly, this targeted quantum dots not only have good target recognition ability, but also have low toxicity and strong light stability. Moreover, confocal laser scanning microscopy (CLSM) showed that the localized fluorescence would be detected around the nucleus of human breast cancer cell MCF7 (high expression of P53) compared with that of T47D (low expression of P53). In summary, we believe that this QDs probe will provide a broad platform for clinical diagnosis and treatment of breast cancer and in vitro studies in future.
\end{abstract}

\section{Introduction}

Breast cancer is the most common malignant tumor in women, and attributed to increased understanding of molecular pathology mortality rate of it has decreased[1]. The tumor suppressor P53 is the transcription factor that controls the cellular fate[2,3]. Functionally, the P53 protein acts as a transcription factor and the mutated P53 was related to the occurrence of many cancers, including breast cancer, esophageal cancer, colorectal cancer, lung cancer, brain tumors and osteosarcoma[4-6].

Quantum dots (QDs) are fluorescent semiconductor nanocrystals, whose basic structure is composed of a core semi-conductor, typically CdSe or CdTe, enclosed in a shell of another semiconductor, such as zinc sulfide (ZnS)[7-9].Relevant experimental data has show that the QDs' quantitative analysis revealed its new optical properties, such as low level of antigen detection samples, which has important significance for the diagnosis and treatment of cancer[10-15]. They have potential applications ranging from medicine to energy [16,17]. Compared with traditional organic fluorophores and fluorescent proteins, QDs are superior in fluorescence brightness, photobleaching resistance, and fluorescence emission tuneability [18].

Here we focused on a new synthesized compound, which could turn QDs into hydrophilic molecules and conjugated with P53 protein via chemical experiments. We then investigate whether this newly synthesized QDs-P53 could combine with the mutational P53 in the breast cancer cells effectively and specifically. Finally we evaluate the in vitro cytotoxicity of the probe to determine the safety in biological applications.

\section{Materials and methods}

\section{Materials}

Human breast cancer cells T47D and MCF-7 were obtained from the China-Japan Union Hospital, Jilin University (Changchun, China). The SP1 clone rabbit anti-human P53 polyclonal antibody was the product of Zhongshan Golden Bridge Bio Company (Zhongshan Golden Bridge 
Bio Co., Ltd, Beijing, China). IgG (from goat serum) and bovine serum albumin (BSA) were purchased from Sigma-Aldrich. AgInS2/ZnS hydrophilic QDs $\left(\lambda_{\text {ex }}=605 \mathrm{~nm}\right)$ (QDs encapsulated with PASP-Na-g-PEG-DDA) were supplied by Alan G. MacDiarmid Institute of Jilin University. N-ethyl-N-(N-dimethylaminopropyl) carbodiiminde (EDC) were purchased from Thermo Scientific Company (Thermo Scientific, Rockford, IL, USA). MTT were purchased from Beyotime Institute of Biotechnology (Nantong, China). Bisphenol A (BPA), $\mathrm{HCl}$, and $\mathrm{NaOH}$ were purchased from Sinopharm Chemical Reagent Co. Ltd. (Shanghai, China) and Aladdin Ltd. (Shanghai, China). Dulbecco's modified Eagle's medium (DMEM) and fetal bovine serum (FBS) were purchased from Sunshine Biotechnology Company (Nanjing, China).

\section{Aqueous quantum dots conjugation}

AgInS2/ZnS QDs were synthesized by a modified method based on the reporte procedure[19].

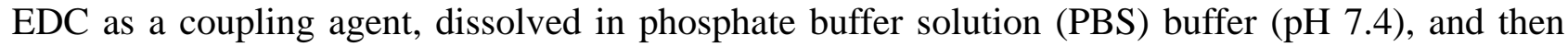
SP1 clone rabbit anti-human P53 polyclonal antibodies were first activated by incubating $500 \mu \mathrm{L}$ of 0.1 mgL-1 antibody solution with $500 \mu \mathrm{L}$ mixture of freshly prepared EDC + sulfo-NHS(0.1mmolL-1) for $15 \mathrm{~min}$ at room temperature (RT,25 $\left.\pm 1^{\circ} \mathrm{C}\right)$. The reaction mixture of QDs were incubated with SP1 clone rabbit anti-human P53 polyclonal antibodies (50 nmol) for $24 \mathrm{~h}$ at ${ }^{\circ} \mathrm{C}$. The EDC and uncombined P53 protein were removed, and ultimately we obtained the P53-targeted QDs (QDs-P53).

\section{Cell culture and fixation}

Human breast cancer cells T47D and the MCF-7 were respectively cultured in DMEM high glucose medium supplemented with $10 \%$ fetal bovine serum $1 \%$ penicillin and streptomycin at $37^{\circ} \mathrm{C}$ with $5 \% \mathrm{CO}_{2}$. Then two cell lines were fixed with $4 \%$ formaldehyde. We used $2 \% \mathrm{wt} . / \mathrm{vol}$. albumin bovine serum to block two cell lines for $30 \mathrm{~min}$ at room temperature to minimize nonspecific binding. Finally, the cells were incubated in $0.3 \%$ Triton X-100 for $10 \mathrm{~min}$.

\section{Fluorescence imaging of QDs labeled cells}

T47D and the MCF-7 cells were incubated with $100 \mu \mathrm{L}$ QDs-P53 probes $(0.2 \mathrm{mg} / \mathrm{mL})$ or mock conjugated QDs $(0.2 \mathrm{mg} / \mathrm{mL})$ for control groups at $37^{\circ} \mathrm{C}$ for $1 \mathrm{~h}$. Add DAPI to the cells for nucleus staining and leave $15 \mathrm{~min}$ for the reaction at $37^{\circ} \mathrm{C}$. Mount the coverslips onto the glass slides and observe the cells by confocal laser scanning microscope (CLSM, Olympus FluoviewFV1000, Japan). Image analysis was performed using FV10-ASW 3.1 Viewer software (Olympus, Japan).

\section{Photostability comparison of QDS-based IHC detection}

QD-based IHC staining was adapted from previously described protocols [20,21]. The fixed and blocked two cell lines were incubated with the QDs-P53 for $4 \mathrm{~h}$ at $37^{\circ} \mathrm{C}$. And then the cells were cultured with either secondary antibody or Alexa Fluor 488-labeled goat anti-rabbit IgG for $2 \mathrm{~h}$ at $37^{\circ} \mathrm{C}$ after another blockade with $2 \%$ BSA for $30 \mathrm{~min}$. As a negative control, primary antibody was replaced by PBS. All cell nucleus were stained with $1 \mathrm{ìg} / \mathrm{mL}$ DAPI. Images were captured with CLSM camera at $1 \mathrm{~min}$ intervals for each color automatically with the same excitation wavelength for $10 \mathrm{~min}$. The same microscope settings were used for both treated and control samples.

\section{In vitro cytotoxicity studies}

Cell viability after QDs exposure was tested by using MTT assay. Human breast cancer T47D and MCF-7 cells were first cultured until cell counts were $4 \times 103$ in each well. Then the culture medium was replaced with $100 \mu \mathrm{L}$ of DMED containing QDs-P53 at different doses $(0.1 \mathrm{mg} / \mathrm{mL}$, $0.2 \mathrm{mg} / \mathrm{mL}, 0.3 \mathrm{mg} / \mathrm{mL}$ to $0.4 \mathrm{mg} / \mathrm{mL}$ ). After $24 \mathrm{~h}, 48 \mathrm{~h}$ and $72 \mathrm{~h}$ of reaction, MTT assay was performed according to the manufacturer's instructions. After removing MTT, 150 $\mu \mathrm{L}$ of DMSO was added. The resulting mixture was shaken about $10 \mathrm{~min}$ at room temperature and the colorimetric measurements were performed at 490nm using the ELx800 Absorbance Microplate Reader (BIO-TEK Instruments, USA). 


\section{Results and Discussion}

\section{Synthesis and properties of QDs-P53}

Fig.1 is a schematic diagram of the QDs-P53. The average size of the synthesized QDs-P53 is about $605 \mathrm{~nm}$. It has been widely proved that single domain antibodies-quantum dot conjugates have been shown to be promising candidates for detection of breast cancer biomarkers [22]. Since the time when the term "quantum dot" has been coined by Reed et al.[23], quantum dots (QDs) have been commonly perceived as inorganic semiconductor nanocrystals. They can exert their interactions with biological structures at the near atomic scale [24]. "Classical” semiconductor QDs have display unique optical characteristics due to the above mentioned quantum confinement effect. To study the spectral properties of the QDs-P53, the UV absorption, photoluminescence (PL) emission and excitation spectra were acquired from the aqueous dispersion of QDs-P53s as illustrated in Fig.2. In Fig.2(a), the characteristic peaks of the QDs which conjugated with the P53 protein still appeared, and the shape of the characteristic peak still existed after the reaction. As shown Fig.2(b), the ultraviolet absorption spectrum of the QDs-P53 could also show the characteristic peak of the QDs. These results show that this chemical reaction does not affect the structure of the QDs. The QD wavelength was $620 \mathrm{~nm}$. This wavelength enables researchers to observe the fluorescent signal under fluorescence microscope.

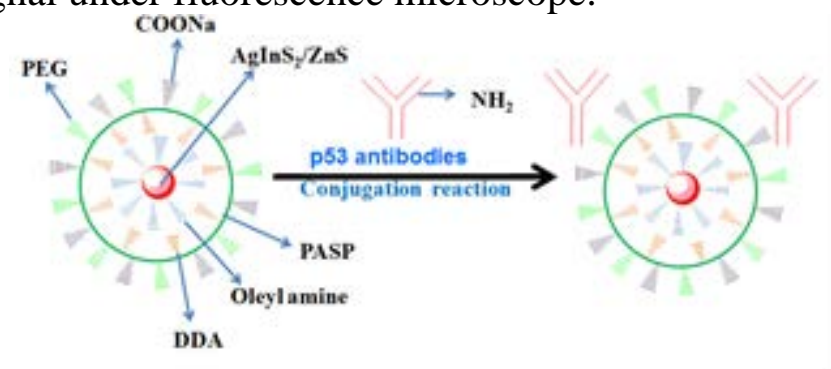

Fig. 1 The schematic diagram of the QDs-P53

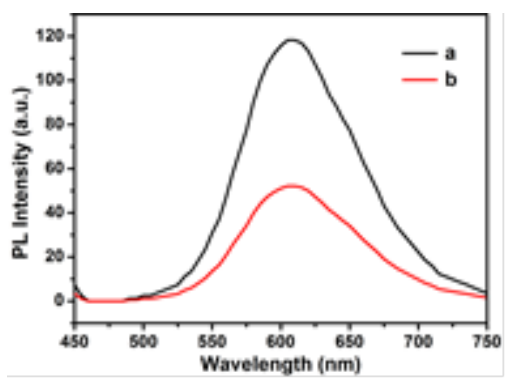

(a)

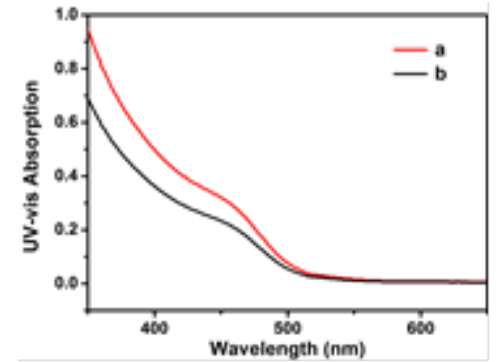

(b)

Fig.2 (a) PL spectra of QDs and QDs-P53, (b)UV-Vis absorption spectra of QDs and QDs-P53

\section{In vitro cell imaging}

Breast cancer cell lines MCF7 (high expression of P53) and T47D (low expression of P53) were reacted with QDs-P53 probes, and observed with CLSM. Fig.3 shows the fluorescence microscopy images of MCF-7 cells after treating with $0.2 \mathrm{mg} / \mathrm{mL}$ QDs-P53. Apparently, QDs-P53s entered into the MCF-7 cells and displayed bright photo luminescence, while the shape and viability of cells show no substantial change, indicating the QDs-P53s can label the cells of MCF-7[ Fig. 3(a)]. In contrast, weak nonspecific binding was observed in T47D cells which had a weak expression of P53 [Fig. 3(b).]. On the control group, in the blank control groups, no fluorescence signal were observed in neither MCF7 nor T47D [Fig. 3(c)]. In conclusion, the fluorescent markers of QDs-P53 probe which we obtained may be applied to in nanotechnology. 


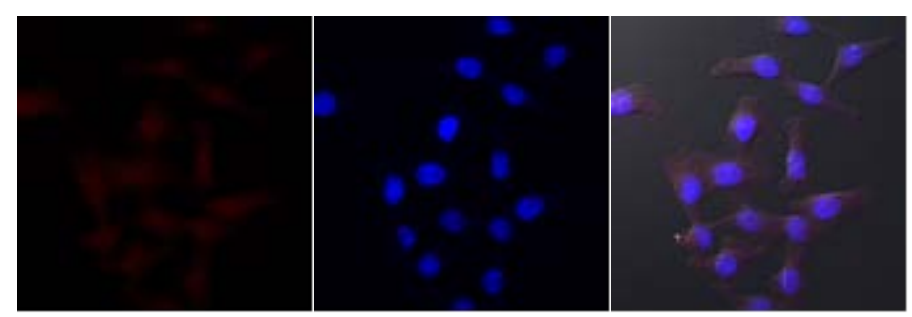

(a)

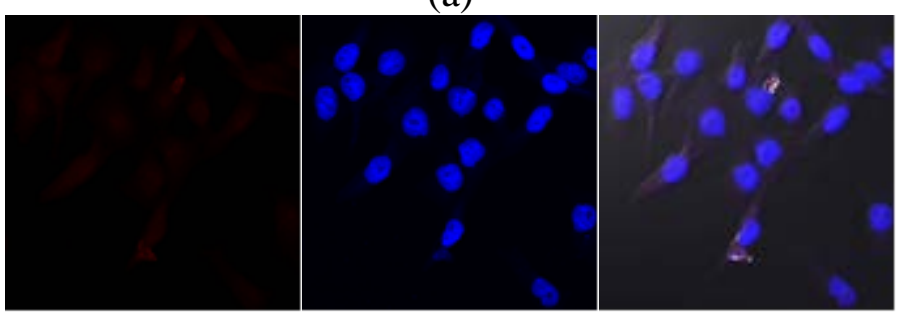

(b)

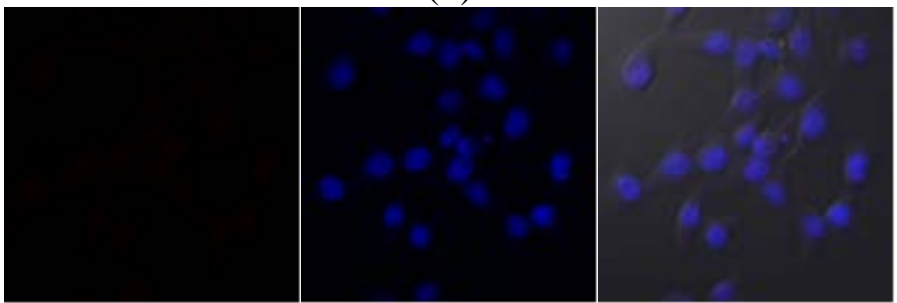

(c)

Fig.3 Confocal microscopy images of MCF7/ T47D cells stained with QDs-P53 and QDs.Cell nuclei were counterstained with DAPI and shown in blue. (a) MCF7 with QDs-P53; (b) MCF7 cells with QDs; (c) MCF7 cells with PBS as blank control.

The optical properties, which deservedly positioned QDs as an outstanding class of fluorescent probes for biomedical imaging, include broad absorption spectra, very narrow and size-tuneable light emission bands along with high resistance to photo bleaching [19-20].The design of QDs for specific targets is achieved via their functionalization with biologically active molecules, such as antibodies, drugs, peptides and small molecular moieties, micelles, etc..In our study, QDs-P53 were able to offer an opportunity to investigate the fine organization of human breast cancer cells at the cytoplasmic and subcellular organelle levels. Evaluation of tumor markers has long been an important part of clinical practice guideline in breast cancer. QDs were recently used for IHC detection in the non-small cell lung cancer clinical samples by Qu et al. The technology of QD-based immunofluorescence for detection of tumor markers in breast cancer had been developed for decades and these studies had the obvious advantages of QDs-based detection than other tradition methods. Chuang Chen et al. successfully conducted a quantitative determination of HRs and HER2 by QD-IHC [21]. Liu et al. used the color technology of quantum dots via simultaneous imaging of HER2 and type IV collagen in cancer tissues. Since the P53 gene is frequently mutated or inactivated in several different cancer types, it is a highly attractive therapeutic target for treating the disease, and P53 mutations are the most frequent genetic alterations in breast carcinomas, reaching $30 \%$ of them [22]. Several reports have mentioned a link between p53 status and response to anthracyclin-based regimen, showing either a better response or a worse response [38]. The photology stability of compound was essential. The QDs were also found to be responsive to the temperature changes [23]. In this study, we compare the fluorescencent stability of organic fluorescent dyes-Alexa Fluor 488 with QDs-P53. The intensity of the QDs-P53 probes had a much more stability in the whole process. By contraries, the light stability of Alexa Fluor 488 decreased rapidly from the beginning of the experiment. We can get the conclusion that the probe of the quantum dot is more stable than the traditional materials in the photology. There are some studies show that the fluorescence of the QDs could still be detected even after one month. Thus,the quantum dot probe is not only suitable for the study of the body, but also in vitro molecular and cell study, for example, long-term observation. 


\section{In vitro cytotoxicity}

In general, all types of QDs should show minimal signs of toxicity if applied in vivo or introduced into human organism following an unintentional exposure40. Therefore, T47D and MCF-7 cells were incubated with QDs-P53 for 24h. T47D and the MCF-7 cells were exposed to the different concentration of QDs-P53 $(0.1 \mathrm{mg} / \mathrm{mL}, 0.2 \mathrm{mg} / \mathrm{mL}, 0.3 \mathrm{mg} / \mathrm{mL}$ to $0.4 \mathrm{mg} / \mathrm{mL})$ at $24 \mathrm{~h}, 48$ $\mathrm{h}$ and $72 \mathrm{~h}$, then we observed and collected the viability data. Our study showed that after $24 \mathrm{~h}$ of incubation, no significant cytotoxicity was registered with QDs-P53 concentrations of up to 100 $\mathrm{mg} / \mathrm{ml}$, which are in good agreement with those in literature [23]. After $48 \mathrm{~h}$ the cell viability of T47D cells changed to $92.3 \%(0.1 \mathrm{mg} / \mathrm{mL}), 93.2 \%(0.2 \mathrm{mg} / \mathrm{mL}), 90.3 \%(0.3 \mathrm{mg} / \mathrm{mL})$, and $90.5 \%$ (0.4 mg/mL), and that of MCF-7 cells changed to $94.7 \%(0.1 \mathrm{mg} / \mathrm{mL}), 96.3 \%(0.2 \mathrm{mg} / \mathrm{mL}), 92.3 \%$ $(0.3 \mathrm{mg} / \mathrm{mL})$, and $91.5 \%(0.4 \mathrm{mg} / \mathrm{mL})$. After $72 \mathrm{~h}$ the viability of T47D and MCF-7 cells decreased by $13 \%$ and $17 \%$ respectively when the concentrations of QDs-P53 reached up to $0.4 \mathrm{mg} / \mathrm{mL}$. The QDs featured low toxicity, were retained within the labelled cells population over days and were redistributed into dividing daughter cells. It was proved that QDs-P53 probes have no obvious cytotoxicity on T47D and MCF-7 cells. Our result is consistent with the literatures that illustrated the dose of QDs had low cytotoxicity and good biocompatibility for cell labeling and imaging after incubating $24 \mathrm{~h}[24]$. At the concentrations typically used in bioimaging applications $(<200 \mathrm{~g} / \mathrm{mL})$, the cytotoxicity of the QDs was found to be marginal.

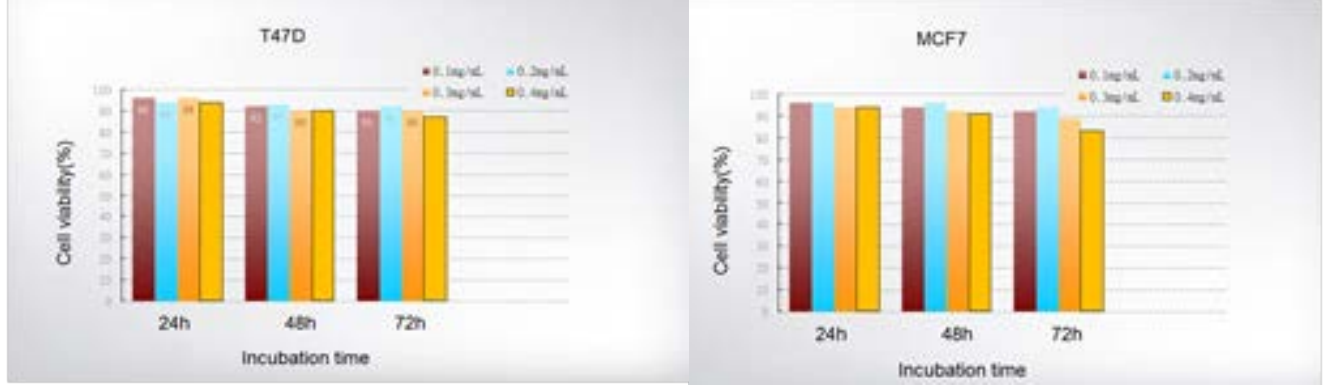

Fig.4. Cell viability of QD-P53 in T47D cells and MCF7 cells.

\section{Conclusion}

In this study, we developed a new QDs-P53 probe. This new probe may enhance our ability to assess breast tumor markers in specimens sensitively. The vitro cytotoxicity experiments also proved that the QDs-P53 probes had no obvious cytotoxicity. Therefore, we have reason to believe that this new type of probe in the future will become an significant technology of diagnosis and treatment of tumor.

\section{References}

[1] Sinn H, Kreipe H. A Brief Overview of the WHO Classification of Breast Tumors, 4th Edition, Focusing on Issues and Updates from the 3rd Edition. Vol 82013.

[2] Vogelstein B, Lane D, Levine A. Surfing the p53 network. Nature. 2000;408(6810):307.

[3] Brown C, Lain S, Verma C, Fersht A, Lane D. Awakening guardian angels: drugging the p53 pathway. Nature Reviews Cancer. 2009;9(12):862.

[4] Kamangar F, Dores G, Anderson W. Patterns of cancer incidence, mortality, and prevalence across five continents: defining priorities to reduce cancer disparities in different geographic regions of the world. Journal of Clinical Oncology. 2006;24(14):2137-2150.

[5] Norberg T, Klaar S, Karf G, Nordgren H, Holmberg L, Bergh J. Increased p53 mutation frequency during tumor progression - results from a breast cancer cohort. Cancer Research. 2001;61:8317.

[6] Mottolese M, Nadasi E, Botti C, et al. Phenotypic changes of p53, HER2, and FAS system in multiple normal tissues surrounding breast cancer. Journal of Cellular Physiology. 2005;204(1):106-112. 
[7] Hardman R. A toxicologic review of quantum dots: toxicity depends on physicochemical and environmental factors. Environmental Health Perspectives. 2006;114(2):165-172.

[8] Hoshino A, Fujioka K, Oku T, et al. Physicochemical Properties and Cellular Toxicity of Nanocrystal Quantum Dots Depend on Their Surface Modification. 2004.

[9] Azzazy H, Mansour M. In vitro diagnostic prospects of nanoparticles. Clinica Chimica Acta. 2009;403(1):1-8.

[10]Peng C, Li Y. Application of quantum dots-based biotechnology in cancer diagnosis: current status and future perspectives. Journal of Nanomaterials. 2010;2010.

[11] Kobayashi H, Hama Y, Koyama Y, et al. Simultaneous Multicolor Imaging of Five Different Lymphatic Basins Using Quantum Dots. 2007.

[12] Wolff A, Hammond M, Hicks D, et al. Recommendations for Human Epidermal Growth Factor Receptor 2 Testing in Breast Cancer: American Society of Clinical Oncology/College of American Pathologists Clinical Practice Guideline Update. Journal of Clinical Oncology. 2013;31(31):3997-4013.

[13]Chan W, Nie S. Quantum Dot Bioconjugates for Ultrasensitive Nonisotopic Detection. Science. 1998;281(5385):2016-2018.

[14] Pelley J, Daar A, Saner M. State of Academic Knowledge on Toxicity and Biological Fate of Quantum Dots. Toxicological Sciences. 2009;112(2):276.

[15]Jin T, Tiwari D, Tanaka S, Inouye Y, Yoshizawa K, Watanabe T. Antibody -ProteinA conjugated quantum dots for multiplexed imaging of surface receptors in living cells. Molecular BioSystems. 2010;6(11):2325-2331.

[16] Tiwari D, Tanaka S, Inouye Y, Yoshizawa K, Watanabe T, Jin T. Synthesis and Characterization of Anti-HER2 Antibody Conjugated CdSe/CdZnS Quantum Dots for Fluorescence Imaging of Breast Cancer Cells. Sensors. 2009;9(11):9332.

[17] Isse K, Grama K, Abbott I, et al. Adding Value to Liver (and Allograft) Biopsy Evaluation Using a Combination of Multiplex Quantum Dot Immunostaining, High-Resolution Whole-Slide Digital Imaging, and Automated Image Analysis. Clinics in Liver Disease. 2010;14(4):669.

[18]Rakovich T, Mahfoud O, Mohamed B, et al. Highly sensitive single domain antibody-quantum dot conjugates for detection of HER2 biomarker in lung and breast cancer cells. ACS Nano. 2014;8(6):5682.

[19]Reed M, Randall J, Aggarwal R, Matyi R, Moore T, Westel A. Observation of discrete electronic states in a zero-dimensional semiconductor nanostructure. 1988.

[20]Bentolila L, Ebenstein Y, Weiss S. Quantum dots for in vivo small-animal imaging. The Journal of Nuclear Medicine. 2009;50(4):493.

[21] Chrisanthar R, Knappskog S, Lokkevik E, et al. Predictive and Prognostic Impact of TP53 Mutations and MDM2 Promoter Genotype in Primary Breast Cancer Patients Treated with Epirubicin or Paclitaxel. PLOS ONE. 2011;6(4):1-10.

[22] Yuan F, Ding L, Li Y, et al. Multicolor fluorescent graphene quantum dots colorimetrically responsive to all-pH and a wide temperature range. Nanoscale. 2015;7(27):11727-11733.

[23] Li W, Zhang Z, Kong B, et al. Simple and Green Synthesis of Nitrogen - Doped Photoluminescent Carbonaceous Nanospheres for Bioimaging. Angewandte Chemie. 2013;125(31):8309-8313.

[24] Song S, Jang M, Jeong J, et al. Primary hepatocyte imaging by multiphoton luminescent graphene quantum dots. Chemical Communications. 2015;51(38):8041-8043. 